incidence and severity of gastric erosions would clearly be minimised if drugs with an erosive influence (corticosteroids) were used sparingly and azathioprine and other cytotoxic drugs that may contribute a bleeding tendency (actinomycin C, cyclophosphamide, antilymphocyte globulin) given in as low a dosage as possible. Patients should also be warned of the danger of aspirin-containing preparations. ${ }^{14}$ Fibreoptic endoscopy and measurement of gastric acidity are therefore necessary to identify patients likely to benefit from prophylactic use of an antisecretory drug, and attention to immunosuppressive drug regimens is equally important. This seems preferable to prophylactic surgery, which is the policy in some dialysis centres. ${ }^{15} 16$

In conclusion, cimetidine may prove to be a considerable advance in the management of peptic ulcer in the uraemic patient and also in the prevention of upper gastrointestinal complications after transplantation.

We thank Sister Elizabeth Crawford and Sister Mabel Lindsay for carrying out the pentagastrin tests; the nursing, technical, and secretarial staff of the renal unit, Belfast City Hospital, and the technical staff of the department of medicine, Royal Victoria Hospital, for their co-operation in this study; and Miss Mary Martin for her secretarial help.

The work was supported by a grant from the Northern Ireland Kidney Research Fund.

\section{References}

${ }^{1}$ Langman, M J S, and Cooke, A R, Lancet, 1976, 1, 680.

2 Canavan, J S F, and Briggs, J D, in Proceedings of the Second International Symposium on Histamine $\mathrm{H}_{2}$-Receptor Antagonists. Amsterdam, Excerpta Medica, 1977.

${ }^{3}$ Doherty, C C, et al, Peptic Ulcer in Chronic Renal Failure. Submitted for publication.

${ }^{4}$ Ardhill, J E S, PhD Thesis, Queen's University of Belfast, 1973.

5 Beeley, L, Prescribers fournal, 1977, 17, 7.

6 Alfrey, A C, LeGendre, G R, and Kaehny, W D, New England fournal of Medicine, 1976, 294, 184.

${ }^{7}$ Barreras, R F, New England fournal of Medicine, 1970, 282, 1402.

8 Burland, W L, et al, Proceedings of the Second International Symposium on Histamine $\mathrm{H}_{2}$-Receptor Antagonists. Amsterdam, Excerpta Medica, 1977.

${ }^{9}$ Fung, W P, Lim, C H, and Tye, C Y, Annals of the Academy of Medicine of Singapore, 1974, 3, 379.

10 Ahonen, J, et al, Proceedings of the XIVth European Dialysis and Transplant Association. London, Pitman, 1977.

11 Starzl, T E, Experience in Renal Transplantation. Philadelphia, Saunders, 1964.

12 Doherty, C C, et al, Proceedings of the XIVth Congress of the European Dialysis and Transplant Association. London, Pitman, 1977.

13 Weiner, S N, Vertes, V, and Shapiro, H, Radiology, 1969, 92, 110.

${ }^{14}$ Doherty, C C, and Mary G McGeown, Lancet, 1977, 1, 1056.

${ }^{15}$ Hadjiyammakis, E J, et al, Lancet, 1971, 2, 781.

${ }^{16}$ Evans, D B, and Smellie, W A B, Clinical Organ Transplantation. Oxford, Blackwell, 1971.

(Accepted 30 September 1977)

\title{
Glutamate dehydrogenase: a reliable marker of liver cell necrosis in the alcoholic
}

\author{
LENA VAN WAES, CHARLES S LIEBER
}

British Medical fournal, 1977, 2, 1508-1510

\section{Summary}

The usefulness of blood enzyme determinations as markers of liver necrosis was tested in 100 alcoholics who underwent biopsy during clinical investigation. Mean values of glutamate dehydrogenase (GDH), serum aspartate and alanine transferase (SGOT and SGPT), ornithine carbamoyltransferase (OCT), and gammaglutamyltranspeptidase (gamma-GTP) tended to rise with increasing liver cell necrosis, though values of SGOT, SGPT, OCT, and gamma-GTP showed considerable overlap between the 32 patients with histologically proved hepatitis and the 68 without. By contrast, GDH values showed virtually no overlap between patients with and without hepatitis, and a value of two and a half times the normal value discriminated between the two groups.

Because of its easy determination and its reliable reflection of liver cell necrosis the GDH concentration should be estimated routinely in alcoholic patients.

\section{Introduction}

Liver cell necrosis is considered to represent an important factor

\footnotetext{
Alcohol Research Centre, Bronx Veterans Administration Hospital, and Mount Sinai School of Medicine, New York

LENA VAN WAES, $M D$, fellow

CHARLES S LIEBER, MD, director
}

in the progression of liver disease. Since repeat biopsies are impracticable for monitoring purposes, spill-over into the blood of the so-called liver enzymes, especially transaminases, is commonly used as a marker of liver cell necrosis. In the follow-up of patients with alcoholic liver disease, however, this approach has proved to be unsatisfactory. Blood transaminase concentrations are a poor reflection of liver cell necrosis. ${ }^{1}$ In alcoholic hepatitis, for example, concentrations of transaminases are only moderately raised and normal values are occasionally found." Moreover, transaminases are not liver-specific and raised concentrations may reflect, at least partly, damage to other organs. $\gamma$-Glutamyltranspeptidase ( $\gamma$-GTP) was recently suggested to be a useful marker of alcoholic liver disease. ${ }^{3}$ But although there is some correlation between raised $\gamma$-GTP concentrations and liver cell necrosis, ${ }^{4}$ raised concentrations may reflect only microsomal induction by alcohol in some cases, $^{5--}$ and increases produced by non-hepatic causes are common.

In an attempt to find a more suitable marker of liver necrosis in alcoholics, we focused on glutamate dehydrogenase (GDH) for various reasons. Firstly, it occurs predominantly in the liver, where its concentration ( $\mathrm{U} / \mathrm{g}$ protein) is 17 times that found in heart muscle, 80 times that found in skeletal muscle, and 28 times that found in pancreas. ${ }^{*}$ Secondly, its activity is $1 \cdot 7$ times greater in the centrolobular part of the liver, where alcoholic liver injury produces its major effects, ${ }^{9}$ than in the peripheral portion of the liver lobule. Thirdly, the enzyme is exclusively intramitochondrial, and mitochondrial damage due to alcohol has been documented. ${ }^{10}$

We tested the usefulness of GDH values in alcoholics by correlating the degree of liver cell necrosis with the blood enzyme value determined on the day of biopsy. Results were compared with those determined by estimating concentrations of conventional enzymes. 


\section{Patients and methods}

One hundred alcoholic inpatients ( 82 men and 18 women; average ethanol intake $90-180 \mathrm{~g}$ /day) who had undergone liver biopsy as part of their clinical investigation were studied. The main reasons for admission were problems related to heavy drinking (delirium tremens or entering a detoxification programme) in 54 patients, gastritis after an alcoholic binge in four, liver-related symptoms (jaundice, ascites) in 33, and miscellaneous conditions (hypertension, ulcer disease, malnutrition) in nine. In 14 patients the presence of alcoholic hepatitis was suspected clinically-that is, the patient was suffering from general deterioration, weight loss, nausea, jaundice, and tender hepatomegaly, with or without fever. In all patients the presence of either symptoms and physical signs incriminating the liver, or increased serum transaminase values with or without raised serum bilirubin and $\gamma$-globulin concentrations, or both, indicated the need for a liver biopsy. None of the patients had overt clinical heart disease, symptomatic myopathy, or pancreatitis, which might have contributed to blood enzyme abnormalities. In all patients blood was drawn for enzyme analysis 30 minutes to four hours before the liver biopsy was performed (by the Menghini or Trucut technique).

Histology-Biopsy specimens were interpreted blindly without knowledge of the patient's identity or blood enzymes. Sections stained with haematoxylin and eosin and trichrome-stained sections were examined for the presence of fat, inflammation, fibrosis, necrosis, and Mallory's hyalin. Twelve patients were diagnosed as having a normal liver, 44 a fatty liver without parenchymal fibrosis, 10 fibrosis, and 34 cirrhosis. All patients with fibrosis and cirrhosis also had some degree of fat infiltration. Typical Mallory bodies were present in 18 . The degree of necrosis was graded as follows: 0-absence of necrosis and parenchymal inflammation; 1 -occasional cell drop-out, often shown by the inflammatory reaction, usually mononuclear in type; 2-scattered foci of necrotic cells in the parenchyma with polymorphonuclear infiltration predominantly in the centrolobular area ("mild alcoholic hepatitis"); 3-diffuse parenchymal necrosis with polymorphonuclear infiltrates ("frank alcoholic hepatitis"). The interpretations of the biopsy specimens made independently by the hospital pathologists concurred well with our diagnoses in that none of the patients with grade 1 necrosis were classified as having alcoholic hepatitis, whereas most of those with grades 2 and 3 were so diagnosed.

Serum enzymes-Plasma was separated immediately and haemolysed samples were discarded. Samples were stored at $-18^{\circ} \mathrm{C}$ until they were analysed, one to five days after the collection. The following enzymes were determined at $37^{\circ} \mathrm{C}$ in duplicate by standard laboratory techniques: aspartate transaminase (SGOT), alanine transaminase $(\mathrm{SGPT}),{ }^{11} \gamma-\mathrm{GTP},{ }^{12} \mathrm{GDH},{ }^{13}$ and ornithine carbamoyltransferase $(\mathrm{OCT})^{14}$; the latter was determined in only 86 of the 100 subjects. The activity of $\gamma$-GTP, OCT, and GDH was not affected by this short storage period and the maximum decrease in transaminase activity was $8 \%$ of the original value. Enzyme control samples both for normal and raised enzyme concentrations (Sigma enzyme control $2 \mathrm{~N}$ and $2 \mathrm{E}$ ) were run with each batch of determinations of transaminases and $\gamma$-GTP, and values were accepted only if they yielded results within $10 \%$ of the manufacturer's quoted values. For GDH and OCT we prepared a serum pool and used this as control.

Normal values for our laboratory were determined in a group of 30 controls ( 12 healthy laboratory workers and 18 non-alcoholic patients with normal routine laboratory test results and without clinical or other evidence of liver diseases or pancreatic, cardiac, and muscle wasting disorders). The upper limits of normal, defined as $2 \mathrm{SD}$ above the mean in the control group, were: SGOT 27 IU/1, SGPT 22 IU/l, $\gamma$-GPT $54 \mathrm{IU} / 1$, OCT $0.47 \mathrm{IU} / 1$, and GDH $4.5 \mathrm{IU} / 1$. According to this definition raised (false-positive) values were found in the control group as follows: SGOT concentrations were raised in two controls, SGPT in one, $\gamma$-GTP in two, GDH in two, and OCT in none. All these false-positive values were, however, still within $3 \mathrm{SD}$ above the mean.

Statistics-Since values for the serum enzymes were not normally distributed, logarithmic conversion of these results was carried out before statistical calculations. Analysis of variance was performed for each of the enzyme values to compare the means in the four groups. Linear contrasts were used to test specific group comparisons, and the significance of these contrasts was tested by Scheffe's multiple comparison procedure..$^{15}$
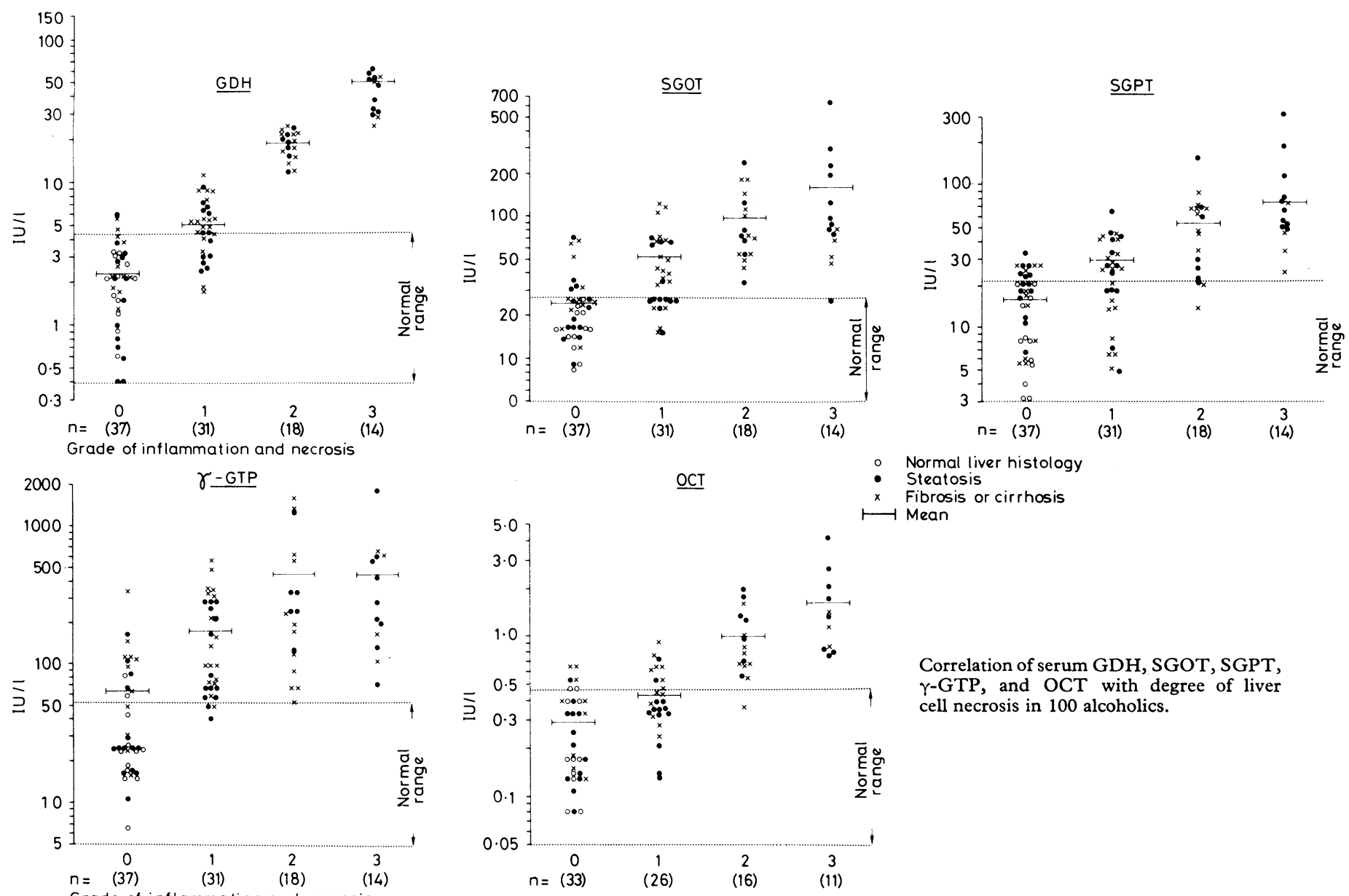

Correlation of serum GDH, SGOT, SGPT, $\gamma$-GTP, and OCT with degree of liver cell necrosis in 100 alcoholics. 
The frequency of the false-positive enzyme values in the control group and the alcoholics was compared by the $\chi^{2}$ test.

\section{Results}

Raised enzyme concentrations were found in most of our alcoholic inpatients: 58 had raised SGOT, 57 raised SGPT, 72 raised $\gamma-G T P$, $41(48 \%)$ raised OCT, and 53 raised GDH concentrations. The correlation of the different enzymes with the degree of liver cell necrosis on biopsy is given in the figure.

\section{PATIENTS WITHOUT NECROSIS AND INFLAMMATION}

Thirty-seven patients (12 with a normal liver, 14 with steatosis, 2 with fibrosis, and 9 with cirrhosis) had no evidence of liver cell necrosis or parenchymal inflammation on liver biopsy. For all enzymes studied the mean values in this group were not significantly different from those in the control group $(P>0.05)$. Abnormal concentrations were found in 8 patients $(22 \%)$ for SGOT, $10(27 \%)$ for SGPT, $13(35 \%)$ for $\gamma-G T P, 3(8 \%)$ for GDH, and 4 out of 33 $(12 \%)$ for OCT. This prevalence of false-positive values was significant for SGPT $(P<0.01)$ and $\gamma-$ GTP $(P<0.005)$. Raised concentrations were only borderline for SGPT, OCT, and GDH but reached much higher values for SGOT and $\gamma$-GTP.

\section{PATIENTS WITH NECROSIS AND INFLAMMATION}

According to the proposed classification 31 patients had grade 1 , 18 had grade 2 , and 14 had grade 3 necrosis and inflammation. Among the 32 patients with alcoholic hepatitis proved on biopsy (grade 2 or 3 necrosis and inflammation) only 14 were clinically suspected of having the condition.

False-negative enzyme values among all those with some necrosis and inflammation were obtained in 13 patients $(21 \%$ for GDH, $18(34 \%$ of 53$)$ for OCT, $13(21 \%)$ for SGOT, and $16(25 \%)$ for SGPT. Only four patients $(6 \%)$ had false-negative $\gamma-$ GTP values. Except for one patient with a low $\gamma-$ GTP concentration and one with a low SGOT concentration false-negative values were always found in the group with grade 1 necrosis and inflammation.

For all enzymes studied there was a tendency for the mean values to rise with increasing liver cell necrosis, and values in patients with mild or frank alcoholic hepatitis (grades 2 and 3 ) were significantly higher than those in patients without hepatitis $(P<0.05)$. As is clear from the figure, however, individual values of SGOT, SGPT, $\gamma-$ GTP, and, to a lesser extent, OCT showed a considerable overlap between the different groups and did not discriminate between individuals with and without hepatitis. For example, serum SGOT concentrations of $50 \mathrm{IU} / 1$ were found in patients without necrosis as well as in those with occasional cell drop-out or those with frank alcoholic hepatitis. By contrast, GDH did not show such an overlap (mean $( \pm 2 S D)$ $5.3+4.74$ in those with grade 1 necrosis $v 18.7+8.2$ in those with grade 2). A serum concentration below $12 \mathrm{IU} / 1$ ( 2.5 times normal) ruled out the diagnosis of alcoholic hepatitis as defined by the criteria used in this study and the independent reading of the hospital pathologists: a level above $12 \mathrm{IU} / 1$ was always associated with significant necrosis and inflammation ( $F$ ratio for discriminant function 219.95 $\mathrm{P}<0.005)$. By using GDH alone, only one misclassification occurred and combining GDH with SGOT ruled out all misclassification in the population studied. GDH had the same discriminatory capacity in the group that was admitted predominantly for alcohol-related symptoms as in the group admitted for liver-related symptoms.

On the other hand, neither GDH nor any of the other enzymes studied indicated the stage of the chronic liver disease, and values in patients with fatty liver were not significantly different from those with cirrhosis for the same degree of liver cell necrosis. Mallory bodies were found only in patients with grade 2 or 3 necrosis. Within these groups there was no significant difference in the GDH values of subjects with and without Mallory bodies (for comparable degrees of inflammation and necrosis)

\section{Discussion}

We have shown the superiority of GDH as a biochemical marker of liver necrosis in the alcoholic. Not only did the mean plasma concentration of GDH rise with increasing liver cell necrosis but, unlike other enzymes, individual concentrations of GDH also clearly discriminated between patients with and without necrosis associated with polymorphonuclear inflammation (alcoholic hepatitis). GDH concentrations also detected cases of alcoholic hepatitis that were clinically silent. The usefulness of this test is further enhanced by its few falsepositive results. Thus, in our series of alcoholics without clinically manifest heart disease, myopathy, or pancreatitis, raised concentrations were less common for GDH than for the other enzymes and all fell in the borderline range.

The predominantly centrolobular intrahepatic localisation of GDH may help to explain the sensitivity of this enzyme in alcoholic liver injury. Indeed, this type of liver disease is characterised by predominantly centrolobular liver injury, and the associated raised GDH is consistent with the observation of high GDH levels in non-alcoholics with acute right-sided heart failure and extensive centrolobular necrosis on liver biopsy. ${ }^{9}$

Results somewhat similar to those obtained for GDH were observed with OCT, another mitochondrial enzyme with a high degree of specificity for the liver. But OCT discriminated between patients with and without alcoholic hepatitis less well than $\mathrm{GDH}$, and the more elaborate technique required for its determination makes it less suitable for routine laboratory use.

None of the enzymes reflected the chronic underlying liver damage, and liver biopsy was required to discriminate with certainty between fatty liver and cirrhosis.

The practical implications of this study are obvious. Because of the technical simplicity of determining GDH and its reliable reflection of liver cell necrosis in the individual alcoholic, estimation of GDH should be included in the investigation of chronic alcoholics. Knowledge of the blood concentration of this enzyme improves our ability to identify patients with active alcoholic liver disease (including those who are asymptomatic) and hence to concentrate our therapeutic effort on those patients.

We thank Dr L Demeulenaere, St Andrieskliniek Tielt, Belgium, for his advice and help in making part of the series available to us; Mr John Saeli and Ms Marie-Anne Verstraete for their expert help in determining the serum enzymes; and Judith Goldberg, department of biostatistics, Mount Sinai School of Medicine (CUNY), for the statistical analysis of the data.

This study was supported in part by the Medical Research Service of the Veterans Administration and USPHS Grants AA-00224, $\mathrm{AA}-03508$, and AM-12511.

Request for reprints should be addressed to Dr C S Lieber, Veterans Administration Hospital, 130 West Kingsbridge Road, Bronx, New York 10468.

\section{References}

${ }^{1}$ Kallai, L, et al, Acta Medica Scandinavica, 1964, 175, 49.

2 Beckett, A G, Livingstone, A V, and Hill, K R, British Medical fournal, $1961,2,1113$.

${ }^{3}$ Rosalki, S B, and Rau, D, Clinica Chimica Acta, 1972, 39, 41.

4 Wu, A, Slavin, G, and Levi, A J, American fournal of Gastroenterology, $1976,65,318$.

${ }^{5}$ Spencer-Peet, J, Wood, D, and Glatt, M M, Lancet, 1972, 1, 1122.

6 Ishii, H, et al, Gastroenterology, 1976, 71, 913.

7 Teschke, R, Brand, A, and Strohmeyer, G, Biochemical and Biophysical Research Communications, 1977, 75, 718.

${ }^{8}$ Schmidt, E, and Schmidt, F W, Klinische Wochenschrift, 1962, 40, 962.

9 Guder, W G, et al, Zeitschrift für Klinische Chemie und Klinische Biochemie, $1975,13,311$.

${ }^{10}$ Lane, B P, and Lieber, C S, American fournal of Pathology, 1966, 49, 593.

11 Sigma Technical Bulletin, No 55-UV.

12 Sigma Technical Bulletin, No 415.

${ }^{13}$ Ellis, G, and Goldberg, D M, Clinical Chemistry, 1972, 18, 523

14 Sigma Technical Bulletin, No 108.

15 Snedecor, G W, and Cochran, W G, Statistical Methods, 6th edn, p 271. Ames, Iowa, Iowa State University Press, 1968.

(Accepted 5 October 1977) 